\title{
A FIGURA DO POETA EM FRIEDRICH VON HARDENBERG (NOVALIS) E GASTON BACHELARD: ALGUMAS CONSIDERAÇÕES ${ }^{1}$
}

Maria Elisa de OLIVEIRA 2

- RESUMO: Através do Fogo - elemento marcante tanto em Novalis (século XVIII) quanto em Gaston Bachelard (século XX), pudemos ensaiar uma aproximação entre esses dois autores, distantes no tempo, mas próximos no tocante à valorização da imaginação (estética).

- PALAVRAS-CHAVE: Universo poético; o elemento do fogo; imaginação; poesia; poeta; conceito; filosofia; razão; devaneio.

Les poètes doivent être la grande étude du philosophe qui veut connaître l'homme. Joubert.

O mundo se faz sonho, o sonho mundo. Novalis.

Indicamos, de início, as obras de Novalis e Bachelard que nos serviram de apoio para o nosso texto. Do primeiro, escolhemos a novela Heinrich von Ofterdingen (1799), por duas razões básicas: o grande destaque nesta obra, apesar de incompleta, da figura do poeta e o fato de este texto ter sido muito comentado e citado por Bachelard, ao longo de quase todas as suas obras (vertente noturna). Tal aspecto sugere-nos que esta produção novalisiana teria, de alguma maneira, influenciado ou, ao menos, exercido um certo reconhecimento por parte do pensador francês. Não podemos esquecer que, segundo Tournier (1989, p.12), Bachelard foi um dos melhores leitores de Novalis.

A restrição de trabalhar apenas com esta obra de Novalis não invalida, contudo, que tenhamos de recorrer a outros textos do poeta alemão, considerados apropriados. O motivo principal desta redução surge da própria pretensão de trabalhar com dois autores, ao mesmo tempo e, como isto não bastasse, nomes - Novalis e Bachelard que desempenharam, individualmente, papel importante no campo da poesia e no da investigação do universo poético.

1 Este texto foi elaborado por ocasião da preparação para o Doutorado (em andamento) na USP, na área de Filosofia.

2 Departamento de Filosofia - Faculdade de Filosofia e Ciências - UNESP - 17525-900 - Marília - SP. 
Do segundo, elegemos do grupo de textos-ensaios a respeito dos quatro elementos (Ar, Água, Fogo e Terra) aquele que trata diretamente do Fogo, isto é, A psicanálise do fogo (1938). Ao lado deste, consultamos também A chama de uma vela (1961) graças à sua proximidade com o elemento do Fogo e, por último, Fragmentos de uma poética do fogo (1988), pelo mesmo motivo. É interessante notar que a primeira obra inaugura a vertente noturna da investigação bachelardiana, ${ }^{3}$ muito embora o texto se encontre ainda numa fase de transição entre a reflexão a respeito de epistemologia científica e aquela em que o pensador francês se põe livremente a devanear, recuperando assim o seu direito de sonhar. Em 1961, decorridos portanto 23 anos da publicação de A psicanálise do fogo e às véspera de sua morte (1962), Bachelard produz um belo e comovente texto, $A$ chama de uma vela, revelando assim que seu psiquismo ainda arde, intensamente, quando medita diante da chama de uma vela.

Por último, recorreremos aos Fragmentos, publicado muito tempo após a sua morte e cuja organização e notas estiveram a cargo de sua filha - Suzanne Bachelard. No prefácio, pois, ela nos conta:

No decorrer de 1959, após a publicação da Poética do espaço (1957) e da entrega ao editor do manuscrito da Poética do devaneio, meu pai empreendeu a redação de um novo livro. Havia tempos acalentava o desejo de retomar o tema inaugural de seus estudos sobre os elementos, o Fogo, segundo uma linha de interesse diferente, que já se tornara manifesta nas duas "Poéticas". Meu pai justificou-a nos textos que publicamos aqui. (1990, p.17)

Tais esclarecimentos provocaram em nós a idéia-sugestão de que o próprio Bachelard se sentiu atraído pelo elemento do Fogo e, nenhum outro elemento, assim o entendemos, suscitou tantos textos e despertou tanto interesse da sua parte. É curioso observar que ao iniciar a chamada fase noturna, com a publicação de A psicanálise do fogo, como já nos referimos, Bachelard, próximo já de sua morte, tenha, de alguma maneira, retornado ao mesmo elemento inicial - o Fogo, como se fechasse um ciclocírculo, só que agora num outro ponto da espiral. O Fogo está assim tanto no início quanto no final de sua jornada onírica.

Poderíamos então indagar qual o papel que este elemento desempenhou na própria economia da obra de Bachelard. Quando, por exemplo, estudamos e tentamos compreender a concepção bachelardiana de imaginação dinâmica, que rompe com os chamados pontos fixos, ${ }^{4}$ instalando uma realidade nova, não podemos deixar de lembrar que o elemento do Fogo suscita em nós a imagem de dinamismo, movimentação e, mesmo, de devir. Ora, para Bachelard, a imaginação é um devir. Daí a sua proposta de uma estética não contemplativa, mas da ação. Todas essas noções serão,

3 A chamada vertente noturna da investigação de G. Bachelard é responsável pela sua visão do unıverso poético. A outra, a diurna, significou basicamente o seu interesse pela investigação científica.

4 Por exemplo, a concepção estática e bem definida do binômio sujeito/objeto; tempo/espaço; continuidade/descontinuidade. 
contudo, oportunamente retomadas, ao longo de nosso texto. Resta esclarecer por que escolhemos o Fogo como elemento que aproxima esses dois autores.

Não é por acaso que em A psicanálise do fogo Bachelard tenha dedicado um capítulo inteiro ao poeta alemão, denominando-o "Psicanálise e pré-história. O complexo de Novalis". Em seguida, em A chama de uma vela, ao meditar diante dela, Bachelard (1989a, p.65) declara que, ao fazê-lo, não poderia deixar de se colocar ao lado de todos os idealistas (Novalis) ao sentir, como eles, o mesmo "estímulo ascensional". Ao aproximar Novalis e Bachelard, pretendemos apenas tecer algumas considerações em torno da figura do poeta e avaliar o que cada um tem a dizer acerca da sua importância.

\section{O filósofo e o poeta em G. Bachelard: o conceito e a imagem}

Sabemos que alguns autores já se propuseram a realizar uma síntese entre a epistemologia e a poética de Bachelard: as suas duas grandes ocupações. Ora, como muito bem observou Felício (1994, p.1): "Os quatro elementos - Água, Ar, Terra e Fogo - apresentam-se como uma síntese entre a epistemologia e a poética bachelardianas. Síntese esta que procura tornar possivel uma coexistência entre as duas partes de seu projeto filosófico, e não simplesmente estabelecer uma justaposição entre elas". Isto posto, ao enfocarmos aqui apenas o elemento do Fogo, permanece, de algum modo, garantida a relação de complementaridade entre os dois campos, acima mencionados, do projeto filosófico bachelardiano. Não nos ocuparemos assim com a discussão e a exposição da possível unidade do projeto filosófico do pensador francês. Cabe-nos, isto sim, indagar dos três tipos - o filósofo, o cientista e o poeta -, qual a importância e o papel que cabe a cada um, no horizonte de suas indagações epistemológicas e no reino do imaginário.

Muitos autores, e entre eles Jupiassú (1976, p.11), gostam de comentar que Bachelard sempre preferiu a companhia dos poetas à dos filósofos. Ao lermos a obra de Bachelard no seu duplo aspecto - Razão e Devaneio -, é possível destacar, com clareza, a provocação com que questiona a filosofia e, conseqüentemente, os filósofos, exigindo-lhes uma reforma de suas posições fundamentais, a fim de que pudessem se colocar em condições de pensar, por exemplo, a novidade das ciências contemporâneas. Neste sentido, Bachelard é implacável tanto com os filósofos quanto com os cientistas, procurando sem cessar, ao longo de toda a sua vida, denunciar os seus conteúdos aparentes, psicanalizando os seus conhecimentos.

E quanto aos poetas? Teria o mesmo Bachelard demonstrado a sua crítica implacável, tanto quanto fez com os cientistas e os filósofos, tudo em nome de um racionalismo aberto para que ambos pudessem compreender a necessidade de re-trabalhar constantemente os conceitos? Como bem observou Jupiassú (1976, p.12), ao comentar o trabalho do pensador francês: "Quando tudo muda na cultura, não podia [Bachelard] admitir a imobilidade da filosofia, defendendo um único ponto de vista, 
e um ponto de vista fixo, para julgar o conjunto das ciências". Ora, não é difícil ao longo das nossas leituras, especialmente dos textos que estão inseridos na chamada fase noturna, notar uma certa preferência de Bachelard pelos poetas e seus trabalhos. Ele os vê, antes de tudo, como amigos e confessa que com eles viveu verdadeiras "festas da amizade".

Talvez pudéssemos entender melhor esta preferência ao analisarmos a natureza da imagem e da imaginação poética em Bachelard. Sabemos que a concepção bachelardiana da imaginação nada tem a ver com a poderosa tradição racionalista e mesmo empirista que sempre abordou a imaginação no contexto de uma explicação sobre a origem e os níveis do conhecimento. A sua investigação se limita aos textos literários, ou mesmo obras de arte, substituindo assim, como lembra Pessanha (1986, p.xiii), "o enfoque psicológico-gnosiológico referente à gênese e à sucessão das etapas do conhecimento, pelo enfoque estético, segundo o qual a imagem é apreendida não como construção subjetiva sensório-intelectual, como representação mental, fantasmática, mas como acontecimento objetivo, integrante de uma imagética, evento de linguagem". O afastamento de Bachelard dessa poderosa tradição que encara a imaginação como um subproduto ou uma mera cópia do real atinge igualmente a psicanálise freudiana e mesmo junguiana, embora, ao longo de seu trabalho, concordasse em muitos aspectos com esta última.

Mas, afinal, qual a novidade que o pensador francês trouxe para a concepção de imaginação e para a imagem $?^{5}$ Antes de tudo lembraríamos que Bachelard estabelece uma distinção entre imaginação formal e imaginação material, na qual a primeira resulta desmaterializadora, considerando da matéria apenas as formas, figurações e feixes de relações. A imaginação material, por sua vez, recupera o mundo e a matéria naquilo que oferecem de concretude e, acima de tudo, resistência (Pessanha, 1986, p.xv). Estes aspectos solicitam a ação do homem que deixa de contemplar o mundo como espetáculo passando então a agente, modificando-o e transformando-o. Completando, Pessanha esclarece: "foi na linhagem do filósofo-voyeur que se desenvolveu toda a tradição intelectualista que concebe a imagem como simples simulacro sem vida e essencialidades próprias - apenas o duplo ou fantasma de um objeto já percebido - e cujo significado deve sempre ser traduzido em conceito" (p.xvi).

No caso de Bachelard, este passará a tomar a imaginação como uma faculdade independente, autônoma em relação à percepção (visual) e que deve ser estudada por si mesma. A sua originalidade se baseia, pois, na recusa de estudar a imaginação, como se ela fosse algo que deveríamos depreciar, em razão de sua submissão àquilo que é "verdadeiro" e "real". Sendo uma função do "irreal", pois cria "irrealidades", a imaginação foi, por conta de uma longa tradição, menosprezada e repudiada. Ora, é contra essa depreciação que Bachelard se insurge.${ }^{6}$ Basta apreciarmos sua afirmação,

5 Lembramos que Bachelard, na sua análise, focaliza especialmente a imagem literária, ou seja, que encontra expressão escrita, na linguagem. Cf., por exemplo, Bachelard, 1989b.

6 Não apenas Bachelard, mas Sartre também se insurge contra essa depreciação, muito embora, na análise do primeiro, fique claro que Sartre cai na armadilha do vício intelectualista que privilegia o visual e o formal em 
para quem: "A imaginação não é como o sugere a etimologia, a faculdade de formar imagens da realidade; ela é a faculdade de formar imagens que ultrapassam a realidade, que cantam a realidade. É uma realidade de sobre-humanidade" (1989a, p.16) (grifos nossos). A partir daí, já podemos começar a estabelecer elementos de ligação entre a concepção bachelardiana de imaginação dinâmica e criadora e a figura do homem-poeta. Acreditamos que nesta relação é de fundamental importância o aspecto de liberdade que envolve não só o poeta, graças ao seu compromentimento com ela, mas também a noção de dinamismo e "autogenia" da imaginação, na concepção de Gaston Bachelard.

Nessa linha de raciocínio, poderíamos afirmar que o conceito perde para a imagem (poética e literária). Tanto Nietzsche quanto Bachelard, como muito bem sublinhou Felício (1994, p.85), denunciam o conceito como uma "metáfora 'petrificada' e 'endurecida', imagem invertida do texto platônico, quando Platão diz que a alma é 'endurecida' pelos banquetes e festins, que a recobrem como se fossem 'algas' e 'conchas', tornando-a irreconhecível". Sem desenvolver aqui a longuíssima tradição da filosofia que estabeleceu a oposição entre filosofia e poesia, considerando a primeira possuidora de um discurso verdadeiro e, portanto, privilegiado, o conceito foi sempre a matéria prima da filosofia. Basta lembrar Hegel, para quem a filosofia é um "trabalho com o conceito". Daí a importância da reflexão nietzscheana (p.84-5), que anula a oposição entre filosofia e poesia, instaurando em seu lugar um confronto/encontro entre ambas. "A metáfora", lembra Felício,

tem a função [agora] de demascarar o conceito, negando a oposição entre o jogo e o sério, entre o sonho e a realidade. A imaginação passa a ter uma função tão importante em filosofia quanto em poesia, permitindo a apreensão das analogias; a reflexão é posterior, intervindo para substituir as analogias por equivalências, as sucessões por relações de causalidade e para estabelecer o conceito. (p.84)

Foi, enfim, nas "pegadas" de Nietzsche, que alguns filósofos reexaminaram a oposição entre o real e o imaginário, a filosofia e a arte, o lógico e o ilógico, o racional e o irracional, abolindo as fronteiras. Este é o caso de Heidegger que, na chamada "segunda fase" de sua investigação, estreita a vizinhança entre arte e filosofia. Nas palavras de Benedito Nunes, "... a terminologia heideggeriana serve bem para descrever o estado atual do affair em que deixa de haver confronto entre filosofia e literatura para instaurar-se uma 'dialogação' num palco compartilhado que é a linguagem” (apud Graieb, 1991, p.1). De onde, então, nos veio a sugestão de que Bachelard, de algum modo, teria privilegiado o poeta e a poesia em detrimento da filosofia e do filósofo?

detrimento do material e da manualidade, como bem sublinhou Motta Pessanha (1986, p.xvii). Nesta questão da depreciação da imaginação e da imagem, consultamos o capítulo esclarecedor de Vera L. G. Felício (1994) intitulado "A autogenia da imaginação", no qual a autora mostra as ligações que há entre Bachelard e Sartre e, especialmente, Nietzsche, ambos responsáveis pela superação da dicotomia e separação entre filosofia e poesia/arte. Mais uma vez, a influência dos alemães se mostra marcante na reflexão do pensador francês. 
Para tanto seria necessário indagar qual o profundo significado da expressão de Bachelard (1986, p.189), quando lemos que o poeta é, de alguma forma, o "guia" do filósofo e do metafísico. Talvez porque o poeta, como o profeta, experimente mais diretamente a emergência das primeiras imagens, descobrindo "um mundo existente além do mundo real [metafísico], não traduzível pela percepção, nem pela razão baseada no princípio da identidade, mas pela imagem literária" (Felício, 1994, p.73). O poeta persegue o novo, não se satisfazendo nunca com as realidades habituais. Seu passo, se compreendemos bem a expressão de Bachelard, está sempre à frente dos demais, pois sua tarefa é abrir novos atalhos na floresta das imagens gerais e racionalizadas. Todavia, Bachelard se expande mais nas entrevistas, revelando o seu afeto pelos poetas. Eis um exemplo:

As pessoas têm medo dos poetas, e com razão. Um poeta incomoda muita gente ... Quando recebo um livro de poesia, experimento grande felicidade. Abandonaria um livro de matemática para ler um livro de poesia ... A poesia dá uma promoção, ela autoriza devaneios pessoais ... Para mim, a poesia é algo de inteiramente solitário ... Pus-me a amar os poetas, infelizmente, demasiadamente tarde ... Meus amigos, os poetas, fazem a felicidade de minha vida ... Se me interesso pela poesia, eu que sou um professor de História e de Filosofia das Ciências, é justamente - não ouso empregar o termo "divertimento", pois não seria digno da poesia - por uma espécie de felicidade. (Chapsal, 1960, p.15-20)

\section{O poeta, na concepção novalisiana}

Podemos dizer que o trabalho empreendido por Bachelard em A psicanálise do fogo (1938), obra de transição, como já mencionamos, foi de depuração, ou seja, um esforço para afastar os chamados "obstáculos oníricos" que perturbam a objetividade da ciência. Trata-se, portanto, de psicanalizar o conhecimento objetivo.

Muito embora obra de transição, surgem já aqui os elementos que definem o "homem-poeta" como alguém que canta o futuro porque libertado do passado. Ao longo desta obra o autor procura ainda demonstrar que "o fogo é, entre os fatores de imagens, o mais dialetizado. Só ele é sujeito e objeto" (s.d., p.190). Só ele, o fogo, revela com perfeição a lei da inversão, de que fala Bachelard. Mais ainda: "Impossível", diz Bachelard "escapar a esta dialética: a consciência de arder é já arrefecer; sentir uma intensidade é diminuí-la; importa ser intensidade sem o saber. Eis a lei amarga do homem agente". E continua, "Só esta ambigüidade é capaz de traduzir as hesitações passionais" (p.191). Ora, só o poeta é capaz de enlaçar elementos contrários, e mesmo opostos, e formar uma unidade. Esta é, aliás, uma das características fundamentais da imagem literária e poética. Só ela é capaz de recusar as leis da lógica tradicional, que não pode admitir que A = B. Como bem observa Octávio Paz (1982, p.120), o poeta pode dizer, por exemplo, que "as pedras são plumas", desafiando, escandalosamente, porque livre, o princípio de contradição. 
A escolha de Novalis, a quem Bachelard dedica um capítulo inteiro, como já mencionamos, se explica, talvez, pelo fato de o poeta alemão reconhecer o calor (fogo) como um elemento profundamente vinculado a um primitivismo e a um animismo. Nas palavras do pensador francês: "Esta poesia [a de Novalis] representa um esforço no sentido da revivescência do primitivismo. Para Novalis, o conto é sempre mais ou menos uma cosmogonia. É contemporâneo de uma alma e de um mundo que se engendram" (Bachelard, s.d., p.73). Mais adiante tentaremos mostrar qual o papel do poeta nesta concepção novalisiana do conto.

Em A chama de uma vela, o autor, já no final de sua vida, expressa mais intensa e belamente a felicidade que é capaz de sentir ao ler os poetas. Assim, lemos:

Quanto a mim, em completa comunhão com as imagens que me são ofertadas pelos poetas, em comunhão com a solidão dos outros, eu me faço sozinho com as solidões dos outros ... O sonhador está à mesa; está em sua mansarda; acende sua lâmpada. Acende uma candeia. Acende sua vela. Então eu me recordo, então eu me reencontro: sou o vigia que ele é ... Sozinho, na noite, com um livro iluminado por uma candeia - livro e candeia, dupla ilha de luz, contra duplas trevas do espírito e da noite. Eu estudo! Sou apenas o sujeito do verbo estudar. Pensar, não ouso. Somente os filósofos pensam antes de estudar. (1989a, p.57-8)

Como ele mesmo declara, trata-se de um livro de "pura fantasia sem a sobrecarga de saber algum, sem [que esteja aprisionado] na unidade de um método de investigação" (p.9). Aqui, o autor-poeta se entrega, plenamente, ao devaneio, já que como ele mesmo confessa: "A chama, dentre os objetos do mundo que nos fazem sonhar, é um dos maiores operadores de imagens" (ibidem). Ainda que o livro não apresente nenhum tipo ou modelo de sistematização, as frases lhe saem livres e soltas como uma fonte que "jorra". Com isto, o texto se assemelha a muitos da chamada prosa moderna. ${ }^{\text {? }}$

O modelo de verticalidade da chama sugere quase que imediatamente o poeta Novalis, considerado por Bachelard um dos "maiores sonhadores da verticalidade". Com ele [Novalis], "deixa-se o reino de uma física de fatos para entrar no reino de uma física de valores ..." (Bachelard, 1989, p.64). O poeta é, pois, aquele indivíduo (criador) que rompe com a vida cotidiana, plana, homogênea e horizontal e instaura uma nova realidade. Comentando a frase novalisiana "Licht macht Feuer", o autor, com três sílabas, como analisa Bachelard, provoca uma revolução ao inverter a seqüência aceita pelo senso comum: "É a luz que faz o fogo". Ora, só o poeta poderia ousar essa "inversão da causalidade", arejando os nossos hábitos. Estas verdades são muito mais frutos da fantasia do que da reflexão.

Em Fragmentos de uma poética do fogo, Bachelard, algum tempo antes de falecer (1962), toma a decisão de reorientar-se em relação às antigas meditações sobre

7 É interessante notar que, em Novalis, o "jato d'água" é um símbolo de inspiração poética, freqüentemente usado pelo poeta alemão, como comenta Marcel Camus (1942). 
o fogo e passa a redigir alguns textos, que depois serão organizados por sua filha e publicados, postumamente. Encontramos uma página reveladora na qual o pensador francês, comparando o filósofo e o poeta, declara:

O filósofo busca o absoluto. Desconfia das imagens, não precisa de imagens. As idéias lhe são suficientes. Tem idéias tão rápidas que elas não são mais idéias ativas. É assim a idéia de nada. O filósofo aplica-a a tudo, sem dar-se conta de que a "aplicação" de toda idéia é a única medida de sua realidade, de sua eficácia. Assim, nada, vazio, não-ser não são manipulados como papel rasgado. Ela permite ao pensamento uma meia-volta no reino das idéias ... O filósofo - esse rei sem reino - reina por sua negatividade... (Bachelard, 1990, p.12)

Já com a idade avançada, não diríamos que Bachelard tivesse se voltado exclusivamente para a poesia e as imagens poéticas; ao contrário, segundo declara sua filha, nele "transparecia [ainda] uma tensão entre a audácia da imaginação livre e o controle de um pensamento instruído. Estava [agora] em jogo, igualmente, a necessidade de tranqüilizar uma imaginação excessiva" (p.16). Todavia, como ele mesmo salienta, "após tanta labuta" deseja agora desenvolver uma "doutrina da espontaneidade". Ora, é na poesia que a linguagem assume liberdade diante de si mesma. A "linguagem imaginada" traz benefícios, como Bachelard mesmo sublinha, ao psiquismo dando origem a uma "alegria de falar". Eis então o seu comentário a este respeito:

Ela é muito simples, essa alegria diante da imagem nova que nos oferece o poeta ... Assim, ao amontoar as imagens dos poetas, acreditei muito tempo, e acredito ainda um pouco, que num simples acolhimento eu poderia conhecer a liberdade de imaginar. Tinha aí um bom começo para a libertação do psiquismo pela poesia. (p.27) (grifo nosso)

E a filosofia, perguntaríamos, poderia igualmente nos proporcionar semelhante libertação? Ao lermos Nietzsche - filósofo-poeta - talvez pudéssemos responder afirmativamente a esta indagação pois, com ele, filósofos (filosofia) e poetas (poesia) não estão em campos opostos. Segundo Benedito Nunes, é possível praticar uma "metaforização" também em filosofia. Nas suas palavras: "Existe um aspecto poético na própria ciência, na medida em que a imaginação se coloca na dianteira, uma hipótese que tem algo de poético (apud Carvalho, 1993, p.5).

Liberado, enfim, do "racionalismo imóvel" Bachelard (1990, p.31) só conheceu o que ele mesmo qualificou de "trabalho tranqüilo ... após ter cortado minha vida de trabalho em duas partes quase independentes, uma colocada sob o signo do conceito, a outra sob o signo da imagem" (grifo nosso). Todavia, mais adiante o autor comenta: "Quero contar agora ... como o devaneio do poeta pode colocar ordem em nós. Que benefício psíquico permanece durante longos meses fiel a uma imagem, fiel à água, fiel a todos os devaneios do vôo dos pássaros. Sou um velho sem músculos; que benefícios, quase musculares, recebi quando colecionava as imagens dos poetas sobre o ferreiro" (ibidem). Contudo, recuperando o equilíbrio e a equanimidade, Bachelard, como num movimento pendular entre doutrina e devaneio, conceito e imagem, pondera: "O filósofo reentrou em uma cena e obrigou o sonhador dos elementos a tentar constituir uma doutrina da imaginação literária" (ibidem). 
Já em Novalis, esse mesmo movimento pendular, entre o pensamento filosófico e o poético, não é tão nítido quanto em Bachelard. Em Novalis, com efeito, o pêndulo insiste em demorar-se mais no pólo poético, embora a distinção clara entre filosofia e poesia seja, no seu caso, bastante artificial, como veremos adiante. Com ele, a necessidade de ser poeta para penetrar nos mistérios do mundo se manifesta, em plena força, por exemplo, na novela Heinnich von Ofterdingen (1942). Todavia, é preciso não esquecer que Novalis pertence à primeira fase do romantismo alemão, juntamente aos irmãos Schlegel, Schleiermacher e Tieck, entre outros, e cuja realização material é de cunho essencialmente filosófico. Na expressão de Eustáquio Barjau (1981, p.10): "Nos autores desta primeira fase, em Novalis de um modo especial, assistimos a uma espécie de versão literária dos grandes sistemas filosóficos do romantismo alemão". Contudo, para Novalis, só o poeta é capaz de apreender a força espiritual que move o Universo (p.18) e de encaminhar o mundo para o Verbo divino. Ainda, segundo Barjau: "Unicamente o poeta é capaz disto; por isso ele é ao mesmo tempo um vidente - seher, porque vê a totalidade do real -, um mago - dichten ist zengen: poetar é engendrar - e um sacerdote, porque esta transformação que se opera pela obra da poesia é uma divinização" (p.19).

Por outro lado, a criação essencialmente livre do poeta é, ao mesmo tempo, uma ação moral. Heinrich von Ofterdingen, num diálogo com Silvestre, dirá: “... há uma impressionante identidade entre um poema sincero e uma nobre ação" (Novalis, 1942, p.385), mostrando assim que os românticos fazem uma identificação entre poesia e moralidade. Cabe então ao poeta a missão de transfigurar o mundo no Verbo divino. Tal concepção foi determinada, basicamente, pela experiência profundamente religiosa que o jovem poeta teve no túmulo de sua noiva, Sofia von Kühn, morta em 1797, depois de dois anos de sofrimento. Este acontecimento desencadeou uma profunda crise na vida de Novalis, com repercussão na sua obra. Diante do túmulo, o poeta alemão apreende o sentido transcendente da morte e a continuidade entre o mundo terreno e o mundo celestial, como revela a série de poemas de Hinos à noite. ${ }^{8}$

A obra Heinrich von Ofterdingen, por sua vez, é um relato (inacabado) que apresenta

as diversas etapas da formação de um poeta até que ele chegue à maturidade. Na primeira parte (A espera) - assistimos à evolução de Heinrich até o momento em que o jovem está preparado para ser poeta. A segunda (A consumação) - devia apresentar a realização desta vocação, ou seja, a obra transfiguradora da Poesia. A novela começa com um sonho no qual o jovem vê uma flor azul - a Poesia. Esta visão foi provocada pelo relato de um estrangeiro que visitou a família de Ofterdingen, despertando no jovem um desejo infinito de encontrar esta flor. Ora, a flor representa o princípio e o fim de toda a obra, ou seja, a evolução espiritual de Heinrich, da flor sonhada para a flor realizada, na verdade, o amor - que na segunda parte devia ser Matilde-Sofia-Cristo - que transfigura, por obra do poeta, todo o real e o devolve ao seio de Deus. (Barjau, 1981, p.29)

8 Os Hinos à noite de Novalis (1987) contêm seis poemas e, destes, o terceiro é central. Nele tomamos contato com a experiência religiosa do poeta, diante do túmulo de sua noiva. 
Nesta espécie de Redenção geral, o poeta tem pois uma função e um papel importantes, já que, na Terra, é o que tem a consciência mais elevada.

Não sendo apenas um divertimento (Camus, 1942, p.32), como a maioria das pessoas pensa, a Poesia, na concepção novalisiana é a mais completa das atividades do espírito, o saber mais profundo e a ação mais eficaz. O poeta é ainda aquele que descobre o eterno, escondido e oculto nas realidades passageiras e efêmeras. Tanto a poesia, quanto o sonho (rêve $)^{9}$ são, na concepção do poeta alemão, profundamente significativos. "No sonho (rêve) entramos em comunicação com as vontades de ser infinito. Eis a razão de serem então proféticos; eles são mais verdadeiros do que a sabedoria limitada dos homens do senso comum" (Camus, 1942, p.33). Ora, a novela Heinnich von Ofterdingen se inicia com um sonho: da Flor azul. "O sonho parece-me ser a salvaguarda contra a regularidade e a banalidade da existência ... Sem os sonhos, certamente envelheceríamos mais depressa e assim poderíamos considerar o sonho ... como um divino viático e como um amável companheiro na nossa peregrinação para o santo sepulcro" (Novalis, 1942, p.77).

Como comentam alguns estudiosos da obra de Novalis, dentre os quais Brion, "Tudo é viagem em Ofterdingen, interminável viagem através dos séculos e dos continentes, através dos reinos da natureza e de fecundas metamorfoses. Sendo ao mesmo tempo conhecimento e ação em todos os terrenos do possível, o mito individual se dilata para diluir-se nas infinitas dimensões do cosmos" (1971, p.93). De qualquer forma, o poeta-herói só chegará à Poesia (Flor azul) quando realizar o amor que sente por uma jovem (Matilde), filha de Klingsohr, o "poeta eterno". O poeta, portanto, nesta concepção, se enlaça com o Amor, ou se destina ao Amor.

Nesta caminhada em direção aos mundos superiores, a presença dos elementos é marcante, especialmente do fogo e da água. Numa clara associação entre a Flor azul e o elemento do fogo, lemos numa passagem do texto: "o velho se dirigiu a ela [Princesa] e com uma humilde deferência convidou-a para que ela se sentasse perto do modesto fogareiro instalado no meio da casa de onde, então, subia sem ruído, brincando, uma ligeira chama azul" (Novalis, 1942, p.119). O poeta, enfim, na concepção novalisiana, não é um indivíduo comum, e sua função é arrancar a humanidade do seu torpor e da banalidade da existência. Ao se definir muito mais pela sua característica visionánia, o poeta deve submeter-se a um processo de verdadeira iniciação, cujas etapas são relatadas, em particular, nesta novela.

O que seria a segunda parte de Heinnich von Ofterdingen, não sabemos. As notas dispersas nos cadernos de Novalis (Brion, 1971, p.114) estão demasiado desordenadas para que se possa avaliar, exatamente, no que teria sido esta "Consumação". De qualquer modo, segundo o comentário de vários estudiosos da obra de Novalis, dentre

9 Notemos que Gaston Bachelard faz uma distinção entre rêve e rêverie, correspondendo, em português, a sonho e devaneio, respectivamente. Rêverie (devaneio) seria um sonho em vigilia, ou um sonho acordado. A partir de 1938, o pensador francês irá se debruçar sobre os fundamentos da legitimidade do devaneio e do sonho, como atividades imprescindiveis não só para a arte, mas para a própria vida. 
eles Brion (p.116), este poema-romance propõe uma extraordinária leitura, levando o leitor a uma aventura intelectual e espiritual, inigualável em toda a literatura romântica. ${ }^{10}$

Quanto à filosofia e ao filósofo, é difícil distinguir, claramente, em Novalis, a poesia da filosofia e vice-versa. Nessa medida, podemos dizer que a poesia novalisiana é filosófica, assim como sua filosofia é poética. Tendo igualmente escrito na forma dos fragmentos, poetar/filosofar é também condensar (dichtung-dichter dichten). No fragmento n.717 do Borrador universal, citado por Rubens Rodrigues Torres Filho (1988, p.24), lemos: "A separação de poeta e pensador é apenas aparente - e em detrimento de ambos -". Para depois completar no Fragmentos de Teplitz, n.473: "A poesia é o genuinamente, absolutamente real. Este é o cerne de minha filosofia. Quanto mais poético, tanto mais verdadeiro" (ibidem).

Ao final, a partir destas considerações acerca da Poesia e do poeta, somos tentados a tecer alguns comentários que nada mais são do que sementes lançadas ao solo do pensamento e da reflexão e que, esperamos, possam dar frutos ("colheitas módicas", como diria Novalis), futuramente. Assim sendo, notamos que o pensador francês, que viveu no século XX, perfeitamente contextualizado no avanço da ciência contemporânea e de posse das principais teses científicas, ao se inclinar para o romantismo alemão da primeira fase (Novalis), privilegia o elemento da imaginação (estética), em face da tradição da filosofia francesa oficial, marcada por um tipo de racionalidade que emana de Descartes (Pessanha, 1986, p.vi). Tal aspecto nos permitiria aproximar o projeto bachelardiano do esforço da Escola de Frankfurt'11 ao propor, igualmente, uma crítica não só aos moldes tradicionais de racionalidade, mas uma redefinição da Razão, abandonando o conflito dicotômico entre Razão e Imaginação; conceito (idéias claras) e imagem.

Ao mesmo tempo, poderíamos ainda indagar se o pensador/devaneador dos elementos (ar, terra, fogo e água) concebe a Natureza tanto quanto os românticos (Novalis), como um organismo vivo, um Todo Inteligente não abandonado à sua estrita opacidade ou reduzido a um puro mecanismo. Que atitude, enfim, Bachelard aconselharia que adotássemos diante do mundo material e do universo sensível? A resposta estaria certamente do lado do sentimento, das paixões e das emoções, como para os românticos. Não sendo especialmente místico como Novalis, Bachelard soube, contudo, como os românticos, perceber a importância, por exemplo, de viver a solidão (1989a, p.107-12). É o que evoca com freqüência Heinnich von Ofterdingen de Novalis.

Ao enfatizarmos a importância do fogo na economia dos elementos bachelardianos, repercute em nós a presença marcante também do fogo na referida obra novalisiana. Associando o Amor e a Poesia, o poeta alemão privilegia o fogo e o calor,

10 Fala-se que Heinnich von Ofterdingen é um verdadeiro "Evangelho do porvir"; "Breviário do romantismo" e mensagem destinada a todos os homens (Brion, 1971, p.115).

11 Para uma informação mais geral acerca do círculo frankfurtiano e o que ele representou para a história da filosofia contemporânea, consultar C. F. Olgária Matos, 1993. 
responsáveis pela "consciência profunda [comenta Bachelard] da felicidade calorífica" (s.d., p.75). A luminosidade fria de Goethe, ou a "ciência visual da luz" é substituída em Novalis pela "consciência do calor íntimo", que penetra. Nas palavras de Bachelard:

Esta necessidade de penetrar, de ir ao interior das coisas, ao interior dos seres, é uma sedução da intenção do calor íntimo ... Esta comunhão pelo interior, esta simpatia térmica, encontrará, em Novalis, seu símbolo na descida no interior da montanha, na gruta e na mina. (1989, p.75-6)

Caberia indagar qual é o elemento predominante em Novalis, averiguando-o e rastreando-o ao longo da sua produção. Arriscaríamos pouco se disséssemos que é o Fogo.

OLIVEIRA, M. E. de. The poet's figure in Friedrich von Hardenberg (Novalis) and Gaston Bachelard: some considerations. Trans/Form/Ação (São Paulo), v.19, p.47-59, 1996.

- ABSTRACT: Through Fire - important element in Novalis (XVIII century) and Gaston Bachelard (XX century), we could try an approach between these two authors, separated in time, but close in the aesthetic's imagination value.

- KEYWORDS: Poetic universe; the fire's element; imagination; poetry; poet; concept; philosophy; reason; daydream.

\section{Referências bibliográficas}

BACHELARD, G. Instante poético e instante metafísico. In: O direito de sonhar.

Trad. J. A. M. Pessanha et al. 2.ed. São Paulo: Difel, 1986. A chama de uma vela. Trad. G. de C. Lins. Rio de Janeiro: Bertrand Brasil, 1989a. L'eau et les rêves. Paris: J. Corti, 1989b.

. Fragmentos de uma poética do fogo. Trad. N. Telles; organização e notas de S. Bachelard. São Paulo: Brasiliense, 1990.

La psychanalyse du feu. Paris: Gallimard, 1949.

BACHELARD, S. Um livro vivido. In: BACHELARD, G. Fragmentos de uma poética do fogo.

Trad. N. Telles; organização e notas de S. Bachelard. São Paulo: Brasiliense, 1990.

BARJAU, E. Introdução. In: Novalis. Hinnos a la noche y Enrique de Ofterdingen. 2.ed. Madrid: Nacional, 1981.

BRION, M. Novalis, Hoffman, Jean-Paul. Trad. M. L. Melcón. Barcelona: Barral Editores S.A., 1971. (La Alemanha Romantica II).

CAMUS, M. Préface. In: NOVALIS. Henry d'Ofterdingen. Paris: Aubier, 1942.

CARVALHO, B. Benedito Nunes liga literatura e filosia. Folha de S.Paulo, São Paulo, 5 set. 1993, p.5. 
CHAPSAL, M. Les écrivains en personne. Paris: Union Générale des Editions, 1960 Coll. 10/18, n.809, p.15-20.

FELÍCIO, G. A autogenia da imaginação. In: A imaginação simbólica nos quatros elementos bachelardianos. São Paulo: Edusp, 1994.

GRAIEB, C. Crítico revê polaridade filosofia-literatura. O Estado de S.Paulo, São Paulo, 8 jan. 1991. Cultura, v.8, n.697, p.1.

JUPIASSÚ, H. Para ler Bachelard. Rio de Janeiro: Francisco Alves, 1976.

MATOS, C. F. O. A escola de Frankfurt: luzes e sombras do Iluminismo. São Paulo: Moderna, 1993. (Coleção Logos).

NOVALIS. Henri d'Ofterdingen. Trad. et préfacé par M. Camus. Paris: Aubier, 1942. (Collection Bilingue).

NOVALIS. Hinos à noite. Trad., seleção, introdução e notas de N. N. Okamnoto e P. Allegrini. Ed. bilíngüe. Mairiporã: Esfinge, 1987.

PAZ, O. A imagem. In: O arco e a lira. Trad. O. Savary. Rio de Janeiro: Nova Fronteira, 1982. p.119-38.

PESSANHA, J. A. M. Introdução. In: BACHELARD, G. O direito de sonhar. Trad. J. A. M. Pessanha et al. 2.ed. São Paulo: Difel, 1986.

TORRES FILHO, R. R. Apresentação. In: NOVALIS. Pólen. Trad., apresentação e notas de R. R. Torres Filho. São Paulo: Iluminuras, 1988.

TOURNIER, M. Novalis e Sofia. In: VON HARDENBERG, F. Os discípulos em Saïs. Trad. do texto de Novalis de L. Bruhein. Lisboa: Hiena, 1989. 